\section{Cureus}

Received 11/10/2013

Review began 11/11/2013

Published 01/05/2014

\section{(c) Copyright 2014}

Saigal et al. This is an open access article distributed under the terms of the Creative Commons Attribution License CC-BY 3.0., which permits unrestricted use, distribution, and reproduction in any medium, provided the original author and source are credited.

\title{
Rotational Pericranial Flap for Repair of Refractory Posterior Fossa Pseudomeningocele
}

Rajiv Saigal ${ }^{1}$, Arnau Benet ${ }^{2}$, William Hoffman ${ }^{3}$, Lawrence R. Lustig ${ }^{4}$, Steven W. Cheung ${ }^{5}$, Michael W. McDermott 6

1. Department of Neurological Surgery, University of California, San Francisco, CA 2. UCSF Dept of Neurosurgery, UCSF Dept of Otolaryngology - Head and Neck Surgery 3. Division of Plastic Surgery, University of California, San Francisco, CA 4. UCSF Dept of Otolaryngology - Head and Neck Surgery 5. Dept of Otolaryngology - Head and Neck Surgery, University of California, San Francisco, CA 6. Department of Neurological Surgery, University of California, San Francisco

$\square$ Corresponding author: Rajiv Saigal, saigalr@neurosurg.ucsf.edu

Disclosures can be found in Additional Information at the end of the article

\section{Abstract}

Skull base approaches requiring retro- or translabyrinthine petrosectomy are frequently used for vestibular schwannoma and cerebellopontine angle tumor removal. One postoperative challenge is pseudomeningocele formation. Primary dural closure is often impractical due to dural shrinkage from cautery, desiccation, and the fact that pre-sigmoid dura is difficult to approximate with the retro-/translabyrinthine approach. Synthetic, allograft, and autograft dural substitutes have been used with varying success rates. Pericranial autograft is a desirable substitute due to lack of immunogenicity, flexibility, and wide availability adjacent to posterior fossa lesions. Autologous fat has been used to pack the pre-sigmoid dural defect in order to effect a watertight seal. However, no method is completely effective.

We present a technical note on use of a vascularized rotational pericranial flap technique for repair of refractory pseudomeningocele after translabyrinthine petrosectomy. In our experience, this technique, when combined with temporary or permanent CSF diversion, allows for definitive dural closure and repair of pseudomeningocele.

Categories: Otolaryngology, Plastic Surgery, Neurosurgery

Keywords: pseudomeningocele, pericranium, autograft, pericranial flap, duraplasty, cerebellopontine angle tumor

\section{Introduction}

Repairing a pseudomeningocele after a skull base approach in association with retro- or translabyrinthine petrosectomy remains a challenging clinical problem. Prior studies have examined a variety of dural substitutes for use when primary dural closure is not possible [1-3]. Many techniques have been suggested, including use of a composite polyglactin 910 / poly-pdioxanone mesh patch [4], monolayer and bilayer collagen matrices [5-9], polytetrafluoroethylene [10-13], crescent durotomies for midline suboccipital craniotomies [14], and autologous pericranium [1, 15]. Of these various dural substitutes, autologous pericranium is favorable due to lack of immunogenic response, low risk of infection, flexibility, and ease of use.

However, there is a paucity of technical reports on the use of a rotational pericranial flap for 
dural substitution. This technique is particularly well-suited for challenging posterior fossa dural repair cases. As in other types of reconstructive surgery [16], a rotational flap offers the benefit of preserving the vascular supply. Plastic and reconstructive surgeons have successfully used vascularized pericranial flaps for reconstruction of congenital cranial malformations [1718], repair of chronic scalp ulcers [19], dura mater reconstruction after decompressive craniectomy complicated by infection [20], orbital [21-22] and nasal septum [23] reconstruction, repair of supratarsal sulcus depression [24], cranial base reconstruction after tumor resection [25], and frontal sinus fracture repair [26]. In this technical note, we utilize the principles of plastic and reconstructive surgery in the implementation of a rotational pericranial flap for closure of a complex posterior fossa wound.

As an illustrative case, we present a 35-year-old female with a history of a $4 \mathrm{~cm}$ right cerebellopontine angle (CPA) schwannoma S/P right transcrural petrosal approach for resection with placement of a lumbar subarachnoid drain. The patient gave written approval for the use of her pictures and case history in this paper. The dura over the temporal lobe was closed with interrupted and running 4-0 Polyglactin 910 suture. It was not possible to achieve a watertight closure of the pre-sigmoid dura, so a collagen matrix dural substitute was placed as a sling to prevent excessive herniation of fat into the CPA and this layer was then covered with a fat graft (harvested from the abdomen) and fibrin sealant. The temporal bone flap was repositioned and secured with titanium plates and screws. Bone reconstruction of the mastoidectomy defect and petrous bone was completed with a porous polyethylene plate implant. Her lumbar drain was opened on postoperative day one to drain a goal of $10-15 \mathrm{cc} / \mathrm{hr}$, but was pulled by the patient on postoperative day two. She was discharged in good condition.

Two weeks postoperatively, she was readmitted with an enlarging pseudomeningocele and signs of intracranial hypotension. A left ventriculoperitoneal shunt was placed as the pseudomeningocele was increasing in size. She was discharged in good condition, but returned one week later with enlargement of the pseudomeningocele. A rotational pericranial flap is ideal to repair a suboccipital wound such as this. Figure 1 shows the axial CT scan prior to repair. 


\section{Cureus}

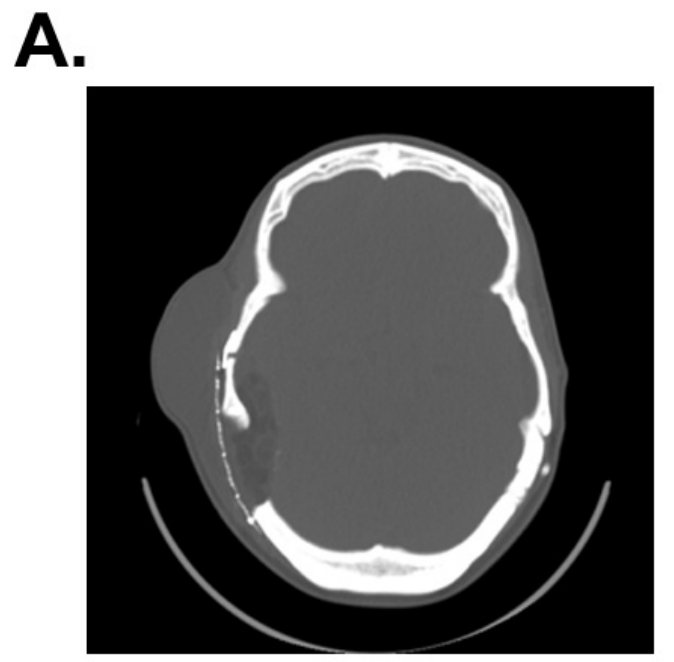

\section{B.}
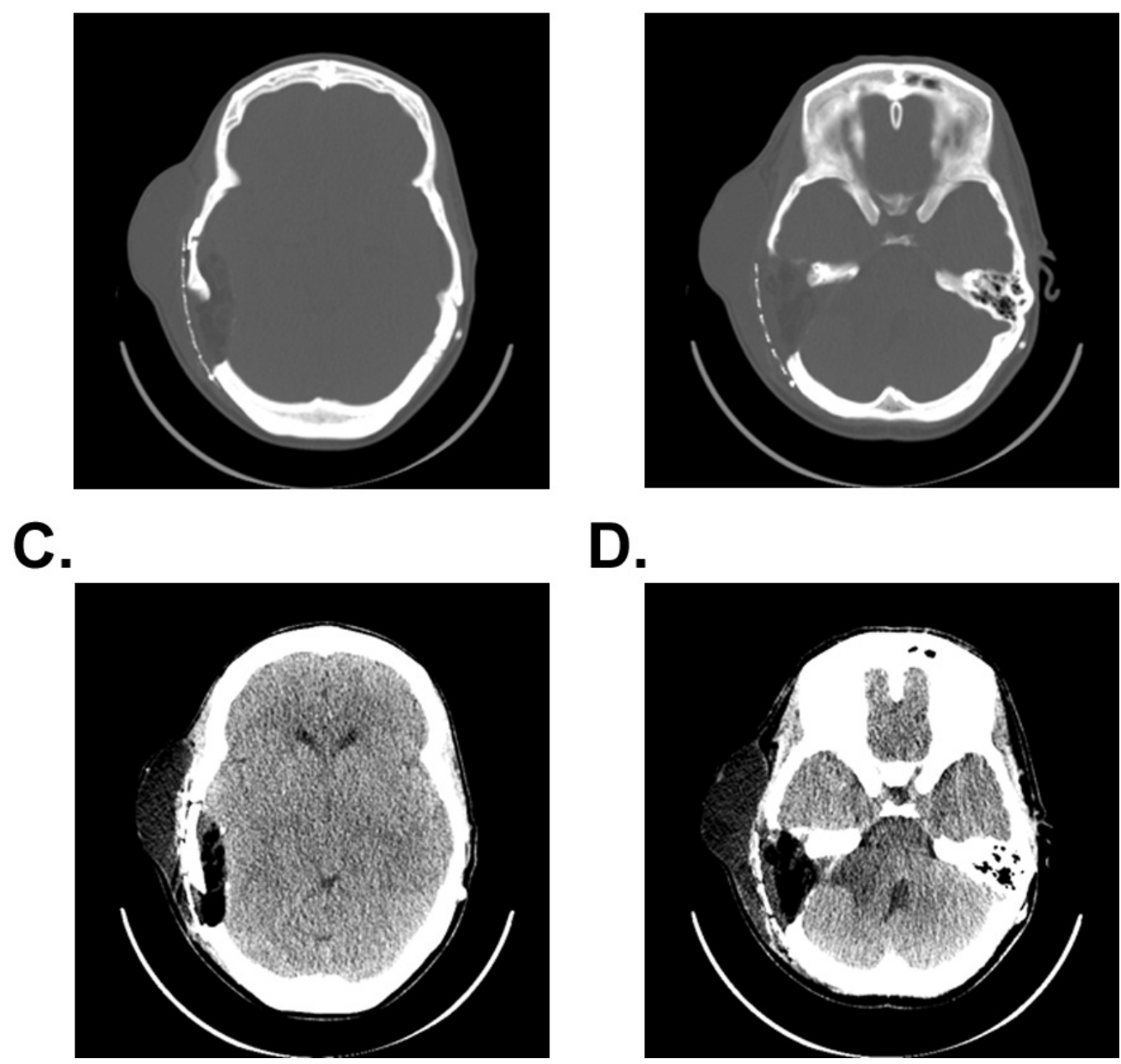

D.

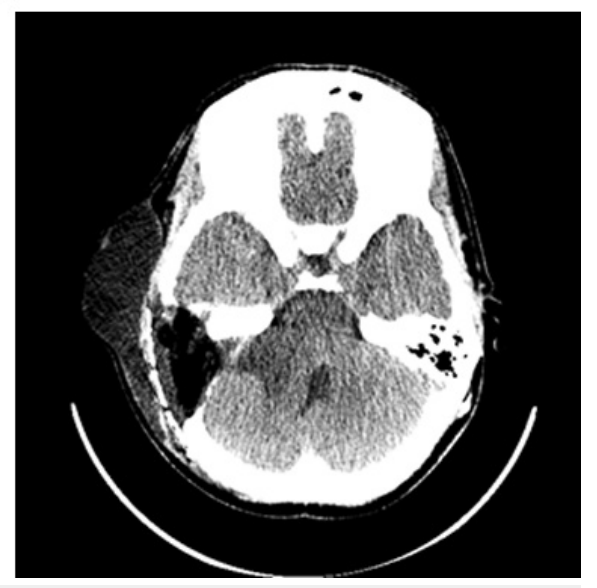

FIGURE 1: Axial CT scan of a 35-year-old female with history of

\section{a $4 \mathrm{~cm}$ right vestibular schwannoma status-post transcrural}

\section{transpetrosal approach for resection.}

She subsequently developed a postoperative pseudomeningocele. Bone (A.) and brain (C.) windows show superior end of petrosectomy and porous polyethylene/titanium plate reconstruction with surrounding pseudomeningocele. Bone (B.) and brain (D.) windows of a more inferior slice further demonstrate the extent of petrosectomy and pseudomeningocele.

In the suboccipital, retromastoid region, the occipital artery runs superficial to the superior oblique capitis muscle towards the supreme nuchal line. On its course, the occipital artery gives branches to the suboccipital muscles: the longisimus capitis, the occipital belly of the occipitalfrontal muscle, and the galea and pericranium of the occipital and posterior portion of the parietal and temporal bones. These branches can anastomose with the vertebral artery. Above the supreme nuchal line, the main trunk of the occipital artery pierces the occipital muscle within the lateral two-thirds of the aponeurosis of the occipital-frontal muscle and becomes superficial to it. However, many branches of variable diameter take off from the occipital artery as it courses through the occipital muscle to feed the pericranium and the parietal bone. These deep branches of the occipital artery are responsible for the blood supply of the proposed rotational flap. 


\section{Cureus}

\section{Technical Report}

\section{Methods}

CSF diversion is recommended for a period of five days as the initial wound healing takes place. If CSF access is not yet available, placement of a lumbar subarachnoid or external ventricular drain is recommended. The drain is left clamped during the procedure. Once CSF access is gained, the patient is positioned semi-lateral with the head turned contralateral to the lesion. The head is positioned on a foam donut head holder, as shown below.

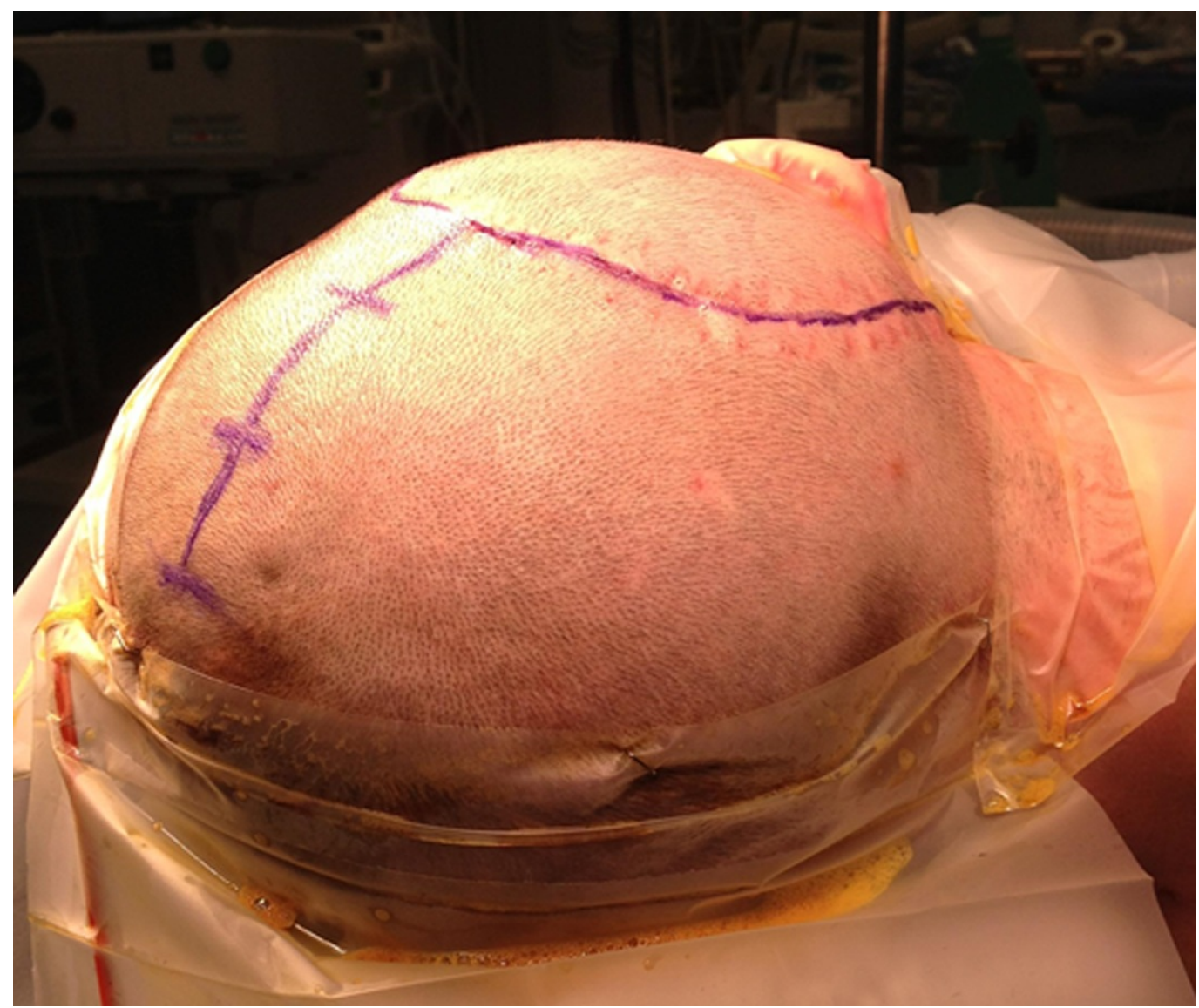

FIGURE 2: Patient positioning

The skin is shaved and prepped in the usual sterile manner. The previous C-shaped skin incision is re-marked, and a straight line is added to allow access to the pericranium over the parietal and occipital bones (Figure 3). The inferior C-shaped incision is re-opened sharply, as shown in Figure 4 below. 


\section{Cureus}

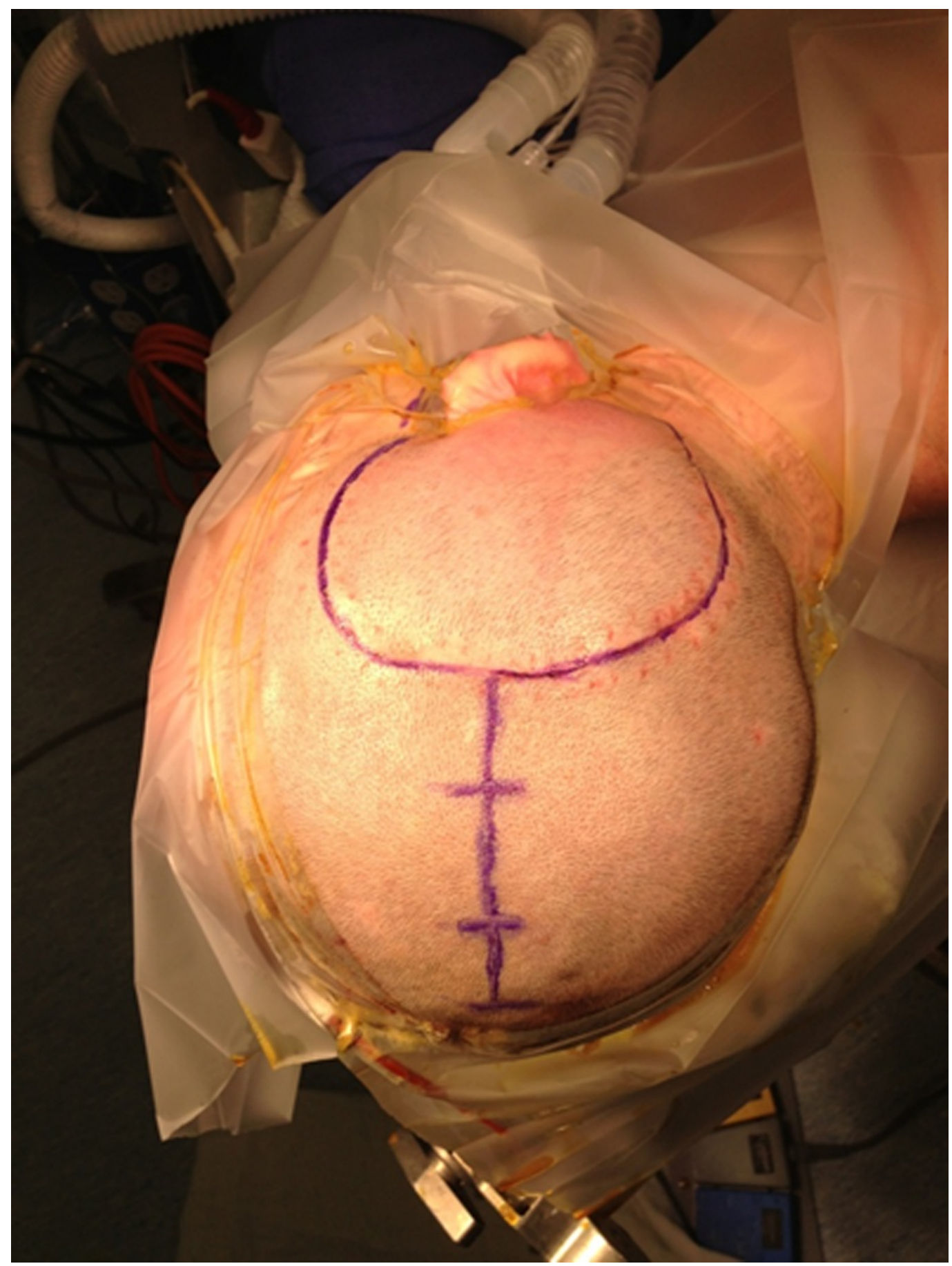

FIGURE 3: Skin incision 


\section{Cureus}

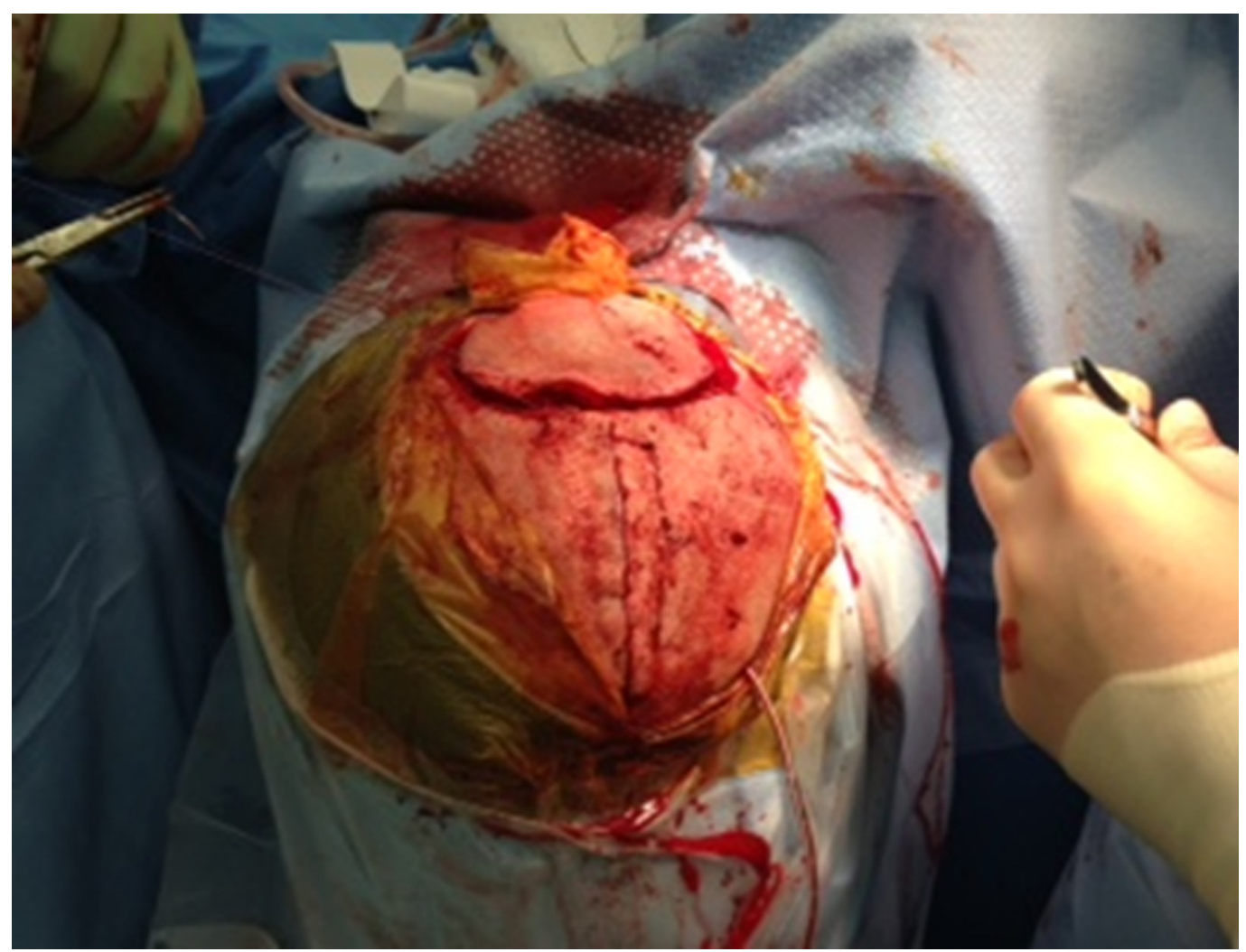

FIGURE 4: Skin incision for opening of inferior C-shaped incision, prior to harvesting pericranium

Subcutaneous soft tissues are divided sharply, stopping short of the pericranium. There, the subgaleal plane above the pericranium is opened with a combination of blunt dissection with Metzenbaum scissors and monopolar electrocautery with a fine Colorado tip. Skin hooks are placed for retraction. The bone flap and porous polyethylene implants are removed. Valsalva is used to investigate the site of CSF leak. Figure 5 shows these various steps in more detail. 


\section{Cureus}

A.

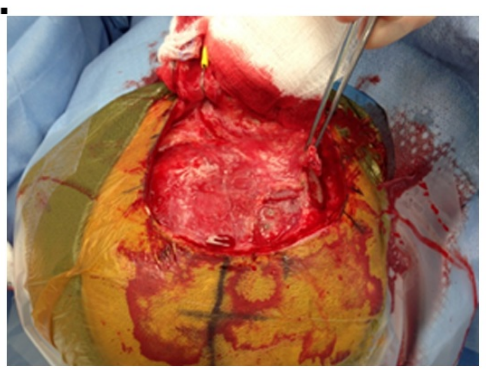

C.

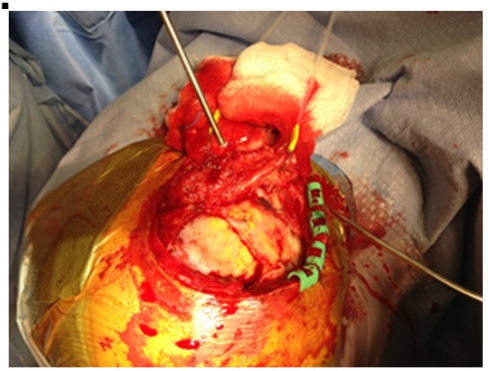

E.

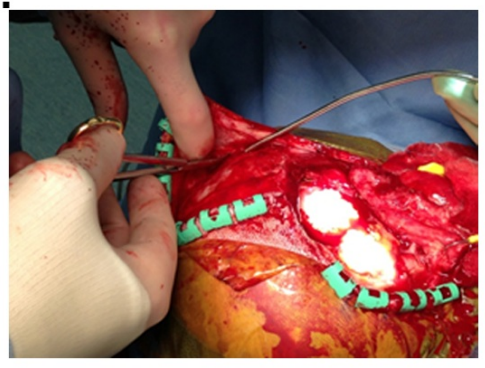

G.

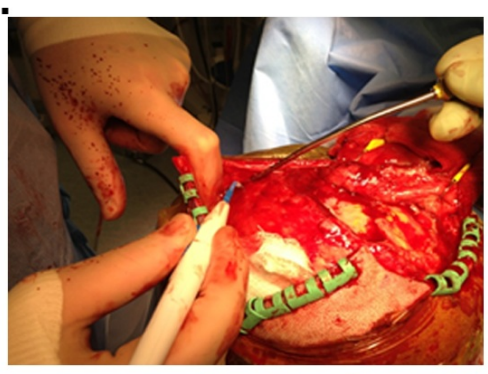

1.

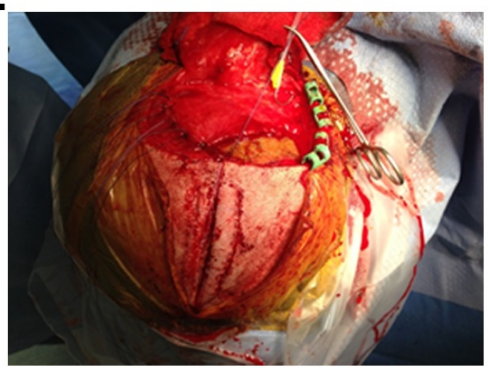

B.

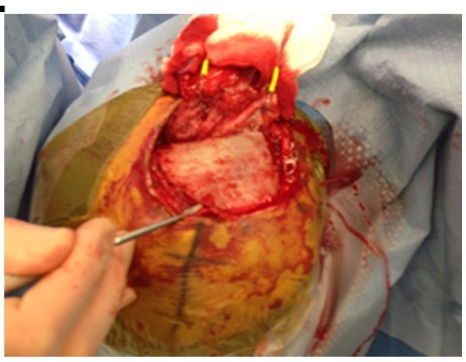

D.

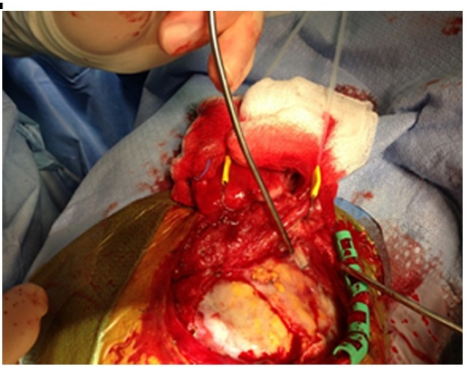

$\mathbf{F}$.

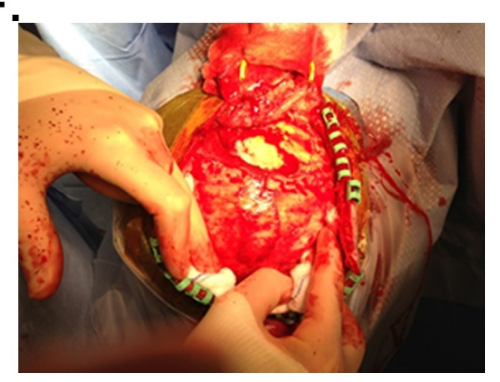

H.

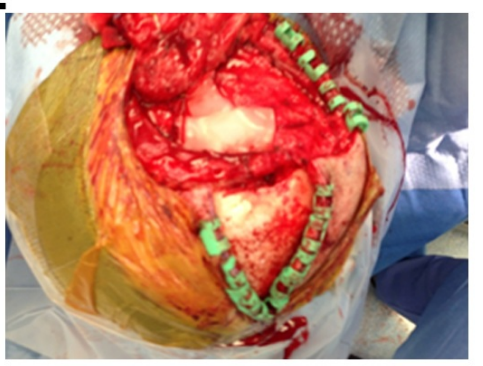

J.

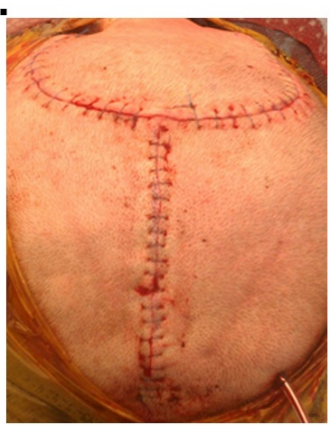

FIGURE 5: Subsequent surgical steps, in sequential order. 
A. The subgaleal layer is re-opened. B. The bone flap is removed. C, D. The epidural fat graft is exposed. E, F. Subgaleal dissection to widen the rostral cranial opening G. Monopolar electrocautery is used to divide the edge of the pericranial flap. $\mathrm{H}$. The pericranial flap is rotated downwards to cover the site of tumor excision. I. The rostral cranial opening is reapproximated first with a galeal closure. J. Skin closure after duraplasty with rotational pericranial flap.

A rectangular pedicle of pericranium is divided with electrocautery anteriorly over the frontal bone, curving around medially under the scalp over the parietal and occipital bones to the superior nuchal line inferiorly and separated from the skull with a periosteal dissector. In order to preserve the vascular supply, the base of the pedicle is the lateral two-thirds of the base of the flap at the superior nuchal line. The medial one-third "back cut" of the pericranium allows for an increased working length of the flap as it is rotated over the posterior fossa, pre-sigmoid, and inferior temporal dura. The pericranial patch is rotated and flapped down to cover the site of leak and surrounding dura. The patch is secured in place with interrupted 4-0 polyglactin 910 sutures at the anterior and inferior margins and covered with fibrin sealant. The wound is washed with copious antibiotic irrigation. A subgaleal hemovac drain is placed. Galea is reapproximated with interrupted 3-0 polyglactin 910 and then closed with a running 2-0 polyglactin 910 . The skin is closed with a running 4-0 monofilament polybutester suture. The final closure is shown in Figure 5J. The wound is then covered with bacitracin ointment, telfa dressing, and a pressure head wrap is applied with a combination of fluffs, kerlex, and a flexinet. The CSF drain is opened to drain a goal of $10-15 \mathrm{~mL}$ per hour on postoperative day one.

\section{Cadaver study}

A postmortem human head was prepared at the skull base and cerebrovascular laboratory to illustrate the surgical anatomy of the pericranial flap. The head was cut at C5 level, and the carotid and vertebral arteries and the jugular veins were cannulated for embalming. The same tubing was used to inject red (arteries) and blue (veins) silicone to ease identification during the surgical simulation procedure.

A standard transmastoid-transcochlear approach was performed in a stepwise manner (Figure 6. The scalp incision was extended anteriorly aproximately $2 \mathrm{~cm}$ around the pinna until the zygomatic process of the temporal bone. A second incision was performed at the superior border of the first incision towards the midline and 10 degrees posteriorly. The scalp was reflected away from the longitudinal incision, and the gale, frontalis, and occipitalis muscles were identified. Next, the frontal and parietal branches of the superior temporalis artery and the supraorbital and the occipital arteries were exposed. The galea was then incised, and a rectangular shaped pericranial flap was raised from anterior to posterior. This maneuver required cutting the suproaorbital artery and distal branches of the supratrochlear artery (Figure 7). Finally, the flap was incised from medial to lateral until the pedicle, which was centered at the occipital artery in the lateral two-thirds of the occipital bone along the nuchal line (back cut technique). The flap was then rotated on its pedicle and placed in the mastoid cavity and floor of the middle fossa uniformly (Figure 8). 


\section{Cureus}

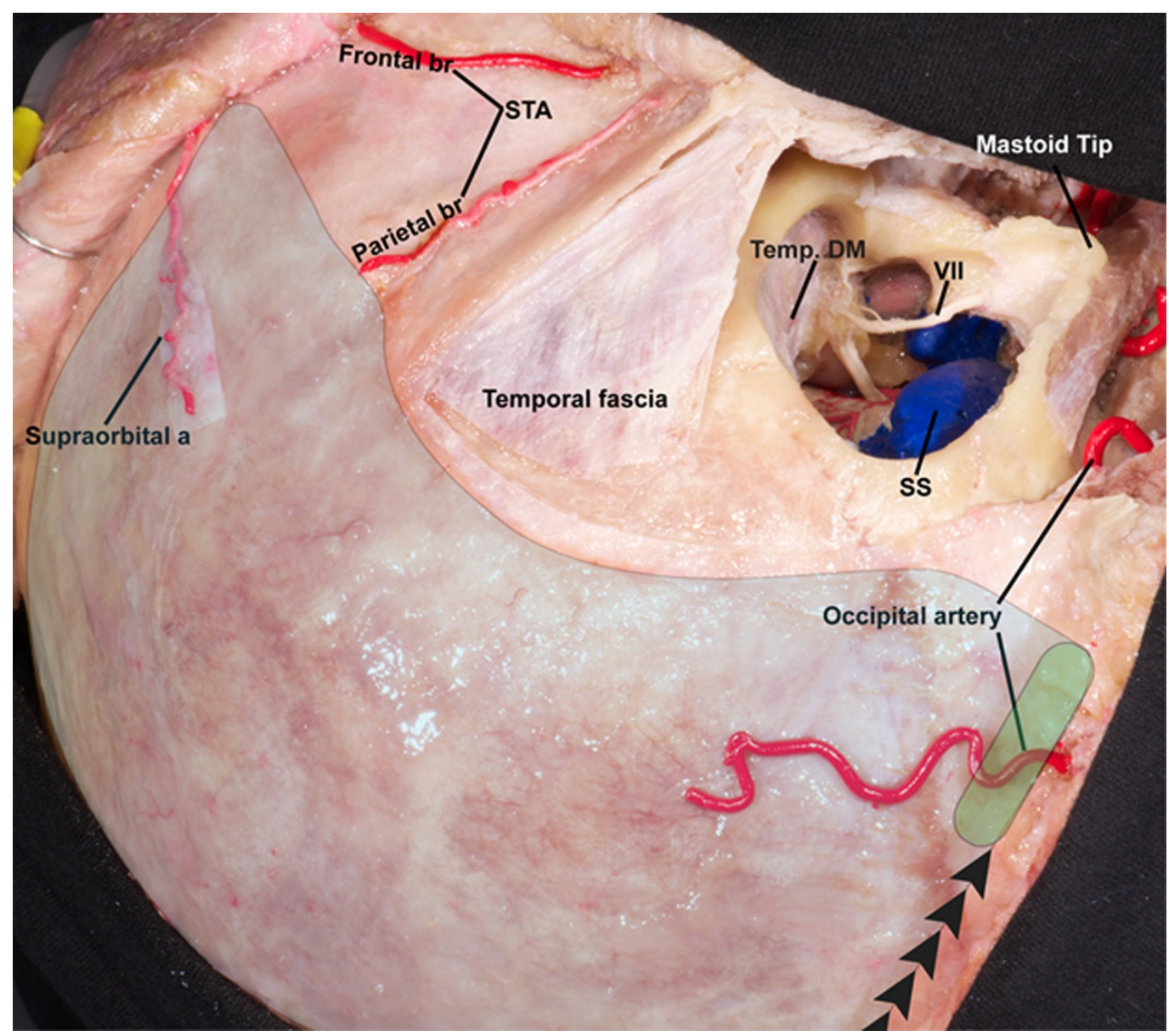

FIGURE 6: Photograph of a cadaver-based surgical simulation procedure for the proposed pericranial rotational flap (blue shading).

A conventional transmastoid-transcochlear approach has been performed in the cadaver. The pericranial flap has been exposed after splitting and reflecting the musculocutaneous layer (scalp and occipito-frontalis muscle). The occipital, superficial temporalis and supraorbital arteries were exposed at the level of the proposed flap. The pericranial flap pedicle (green shading) is located along the lateral two-thirds of the supreme occipital line. Arrowheads show the location of the back cut. Abbreviations: a, artery; br, branch; SS, sigmoid sinus; STA, superficial temporal artery. 


\section{Cureus}

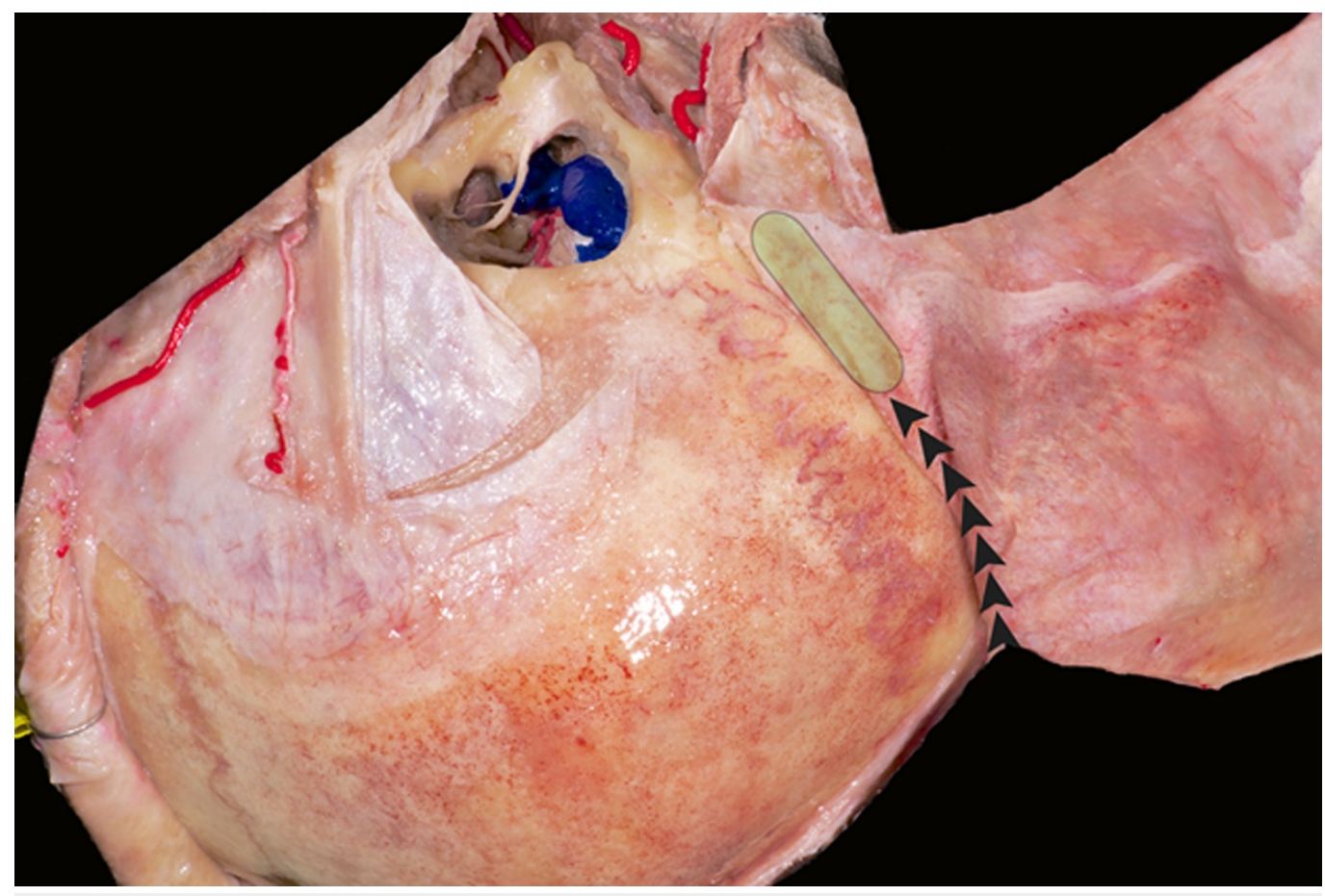

FIGURE 7: Photograph of a surgical simulation of the transmastoid-transcochlear approach and pericranial rotational flap elevation in cadaver.

The pericranial flap was cut at its lateral, medial and anterior limits and prepared for the back cut technique (arrowheads) along the medial one-third of the supreme occipital line. Green label, flap pedicle.

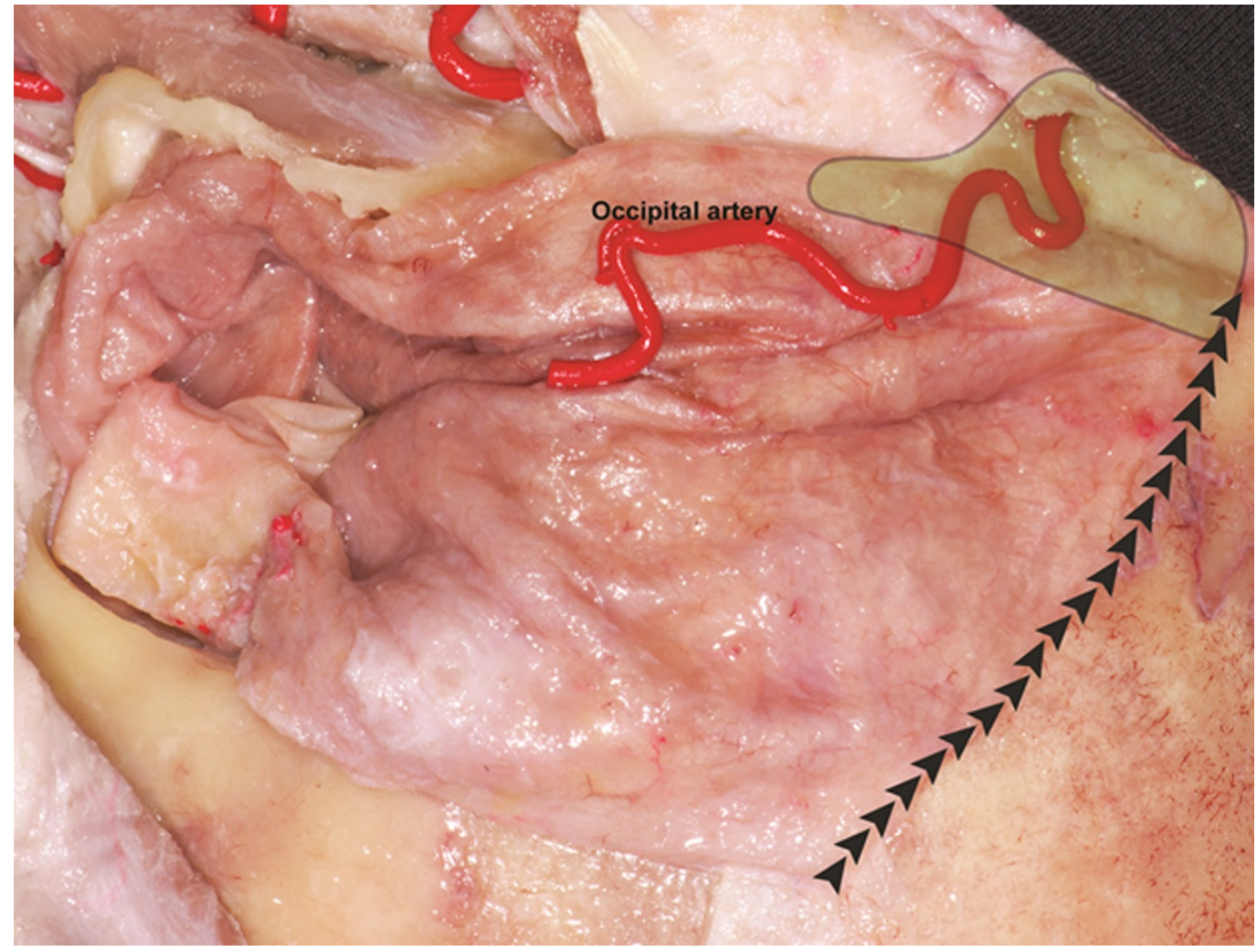




\section{Cureus}

\section{FIGURE 8: Photograph of the flap positioning for closure of the}

transmastoid defect.

The posterior edge of the pericranial flap was back cut (arrowheads) until the pedicle around the occipital artery and rotated laterally towards the mastoid defect. The flap covered the defect completely without any tension on the pedicle.

\section{Results}

The rotational pericranial flap allows for closure of complex suboccipital wounds, such as shown here, which were refractory to primary dural closure or other common dural substitutes and methods of CSF diversion. In the senior authors' (MWMcD, WGH) clinical experience, the rotational pericranial flap has been used successfully for recalcitrant pseudomeningocele wound repair with success. Three such patients had no recurrence of their pseudomeningoceles.

A.

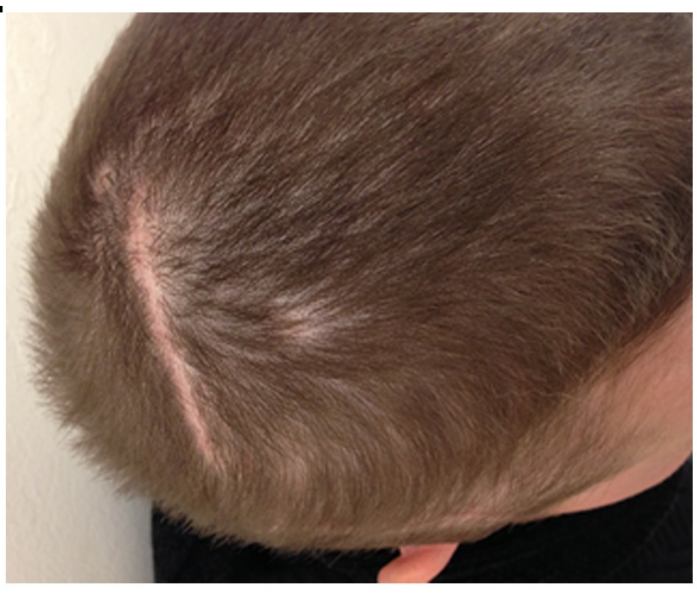

B.

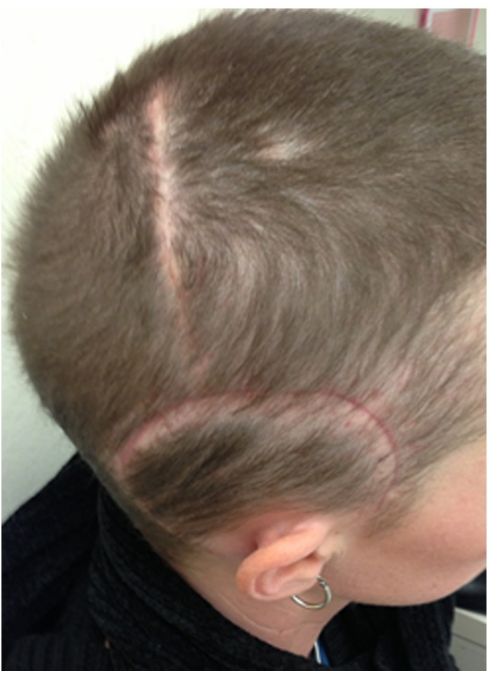

C.

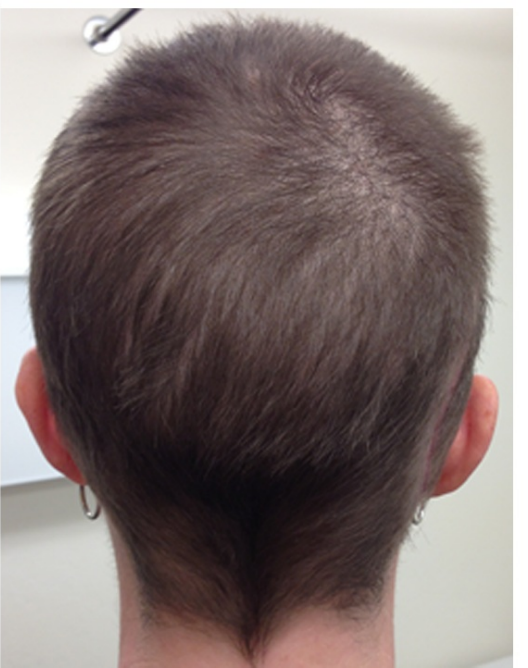

FIGURE 9: Cosmetic result after wound healing.

A. Top view B. Superolateral view C. Posterior view 


\section{Discussion}

Pericranial flaps are versatile and have long been used to reconstruct face, ear, and anterior skull base defects [27]. Here, we described the vascularized, rotational pericranial flap for closure of complex posterior fossa wounds. As pericranial harvest requires a larger incision, it may not be desirable for upfront closure in all cases at the first operation. However, as the incision is hidden in hair-bearing scalp, it allows for excellent cosmesis once healed. Permanent CSF diversion with an indwelling shunt may be needed in some of these cases. We recommend a minimum of period of five days of temporary CSF diversion using a lumbar drain or external ventricular drain after the pericranial flap repair. These drains can be clamped to evaluate for reaccumulation of subgaleal fluid or ventricular enlargement.

Vascular supply considerations are important in this procedure. The deep (periosteal) branch of the occipital artery supplies the pericranial flap [28]. The occipital artery runs over the superior oblique capitis muscle and pierces the occipitofrontal muscle aponeurosis in a variable location within the lateral two-thirds of the supreme occipital line. We find very important to respect the lateral two-thirds of the flap at its pedicle to preserve the main trunk of the occipital artery as well as many branches to the periostium. If a large periostium flap is needed, the occipital artery can be further dissected from the occipital belly of the occipitofrontalis muscle to identify and preserve more flap feeders. Also, we describe the back cut technique to allow the rotation of the flap towards the mastoid defect without stretching the pedicle, which minimizes the risk of flap retraction and wound dehiscence.

The cadaver simulation models the surgical technique, but with some important distinctions. In surgery, the scalp is raised with the galea and the occipital and STA vessels would be in the galea, not on the pericranial flap. The cadaver dissection was completed in order to show the relationship of the occipital artery to the flap as it is mobilized. The occipital artery can be followed and dissected away from the galea as it continues to give perforators to the pericranial flap. Large vessels seen in the cadaver dissection show the arteries available to base the pericranial flap on. We stopped dissecting and transected the occipital artery after the last observed perforator. Thus, the artery is mobilized with the flap in the cadaver simulation to demonstrate the anatomical features difficult to see in surgery. In doing so, the simulation shows the maximal reach of the occipital artery and that there are perforators that attach it to the flap and make it viable.

One area of potential concern is the possible devascularization of the scalp and long-term wound healing after a large scalp incision. Unlike the cadaver simulation, in surgery, the occipital artery is not dissected from the galea so the scalp is not is not heavily devascularized as it is shown in the cadaver image. Small penetrating branches of the artery below the base of the flap are likely enough to provide vascualrity for the flap over its length and provide the desired clinical result. However, one could preserve the perforators until further anterior along the course of the occipital artery, as demonstrated in the cadaver. Most importantly, the length of occipital artery is available for vascular rescue if needed. We have not had any scalp necrosis or wound healing problems in any of the three patients who have undergone this procedure. The rotational pericranial flap aided wound healing since the fluid collection was eliminated.

\section{Conclusions}

Skull base approaches requiring retro- or translabyrinthine petrosectomy are associated with the development of CSF collections in the postoperative period. Pseudomeningoceles that persist despite temporary or permanent CSF diversion may require additional surgical attempts at closure of the CFS fistula. The posteriorly and inferiorly-based rotational parietal-occipital pericranial flap described here works well, presumably by providing a living, vascular tissue. 
Surgeons should consider this technique for recurrent pseudomeningocele cases.

\section{Additional Information \\ Disclosures}

Human subjects: Consent was obtained by all participants in this study. Animal subjects: All authors have confirmed that this study did not involve animal subjects or tissue. Conflicts of interest: In compliance with the ICMJE uniform disclosure form, all authors declare the following: Payment/services info: All authors have declared that no financial support was received from any organization for the submitted work. Financial relationships: All authors have declared that they have no financial relationships at present or within the previous three years with any organizations that might have an interest in the submitted work. Other relationships: All authors have declared that there are no other relationships or activities that could appear to have influenced the submitted work.

\section{References}

1. Lam FC, Kasper E: Augmented autologous pericranium duraplasty in 100 posterior fossa surgeries--A retrospective case series. Neurosurgery. 2012, 71:ons302-307. 10.1227/NEU.0b013e31826a8ab0

2. Parizek J, Mericka P, Nemecek S, Nemeckova J, Spacek J, Suba P, Sercl M: Posterior cranial fossa surgery in 454 children. Comparison of results obtained in pre-CT and CT era and after various types of management of dura mater. Childs Nerv Syst. 1998, 14:426-39.

3. Moskowitz SI, Liu J, Krishnaney AA: Postoperative complications associated with dural substitutes in suboccipital craniotomies. Neurosurgery . 2009, 64:ons28-34.

4. Verheggen R, Schulte-Baumann WJ, Hahm G, Lang J, Freudenthaler S, Schaake T, Markakis E: A new technique of dural closure--Experience with a vicryl mesh . Acta Neurochirurgica. 1997, 139:1074-1079.

5. Danish SF, Samdani A, Hanna A, Storm P, Sutton L: Experience with acellular human dura and bovine collagen matrix for duraplasty after posterior fossa decompression for Chiari malformations. J Neurosurg. 2006, 104:16-20.

6. Litvack ZN, West GA, Delashaw JB, Burchiel KJ, Anderson VC: Dural augmentation: Part 1Evaluation of collagen matrix allografts for dural defect after craniotomy. Neurosurgery. 2009, 65:890-897.

7. Narotam PK, Qiao F, Nathoo N: Collagen matrix duraplasty for posterior fossa surgery: Evaluation of surgical technique in 52 adult patients. Clinical article. J Neurosurg. 2009, 111:380-386.

8. Narotam PK, Reddy K, Fewer D, Qiao F, Nathoo N: Collagen matrix duraplasty for cranial and spinal surgery: A clinical and imaging study. J Neurosurg. 2007, 106:45-51.

9. Nathoo N, Narotam PK: Collagen matrix duraplasty. J Neurosurg. 2009, 110:192-193.

10. Attenello FJ, McGirt MJ, Garces-Ambrossi GL, Chaichana KL, Carson B, Jallo GI: Suboccipital decompression for Chiari 1 malformation: Outcome comparison of duraplasty with expanded polytetrafluoroethylene dural substitute versus pericranial autograft. Childs Nerv Syst. 2009, 25:183-190.

11. Shimizu S, Koizumi H, Kurita M, Utsuki S, Oka H, Fujii K: Duraplasty in the posterior fossa using a boat-shaped sheet of expanded polytetrafluoroethylene. Neurologia MedicoChirurgica. 2007, 47:379-381.

12. Miyake S, Fujita A, Aihara H, Kohmura E: New technique for decompressive duraplasty using expanded polytetrafluoroethylene dura substitute--Technical note. Neurologia MedicoChirurgica. 2006, 46:104-106.

13. Nakagawa S, Hayashi T, Anegawa S, Nakashima S, Shimokawa S, Furukawa Y: Postoperative infection after duraplasty with expanded polytetrafluoroethylene sheet. Neurologia MedicoChirurgica. 2003, 43:120-124.

14. Panigrahi M, Krishnan SS, Varma DR: Crescent posterior fossa durotomy for occipitomarginal venous sinus preservation: A pilot study. Acta Neurochirurgica. 2012, 154:21152121. 
15. Stevens EA, Powers AK, Sweasey TA, Tatter SB, Ojemann RG: Simplified harvest of autologous pericranium for duraplasty in Chiari malformation Type 1. Technical note. J Neurosurg Spine. 2009, 11:80-83.

16. Shonka DC, Jr., Potash AE, Jameson MJ, Funk GF: Successful reconstruction of scalp and skull defects: Lessons learned from a large series. The Laryngoscope. 2011, 121:2305-2312.

17. Wolfe SA: The utility of pericranial flaps . Annals of Plastic Surgery. 1978, 1:147-153.

18. Okumoto T, Iijima Y, Yoshimura Y: Treatment of cranium bifidum occultum of the frontonasal region with a pericranial flap. J Plast Reconstr Aesthet Surg. 2012, 65:e64-66.

19. Yoon SH, Burm JS, Yang WY, Kang SY: Vascularized bipedicled pericranial flaps for reconstruction of chronic scalp ulcer occurring after cranioplasty. Arch Plast Surg. 2013, 40:341-347. 10.5999/aps.2013.40.4.341

20. Takagi M, Kiyokawa K, Sakamoto A, Watanabe K, Rikimaru H, Inoue Y, Shirouzu T: Two-stage reconstructive surgery of a patient with head trauma resulting in extensive cranial bone and dura mater loss caused by postoperative infection: Usefulness of a pericranial flap for dura mater reconstruction. J Craniofac Surg. 2006, 17:584-590.

21. Okumoto T, Koike G, Yoshimura Y: Secondary reconstruction of a mobile eye socket 30 years after enucleation of the eyeball for retinoblastoma: A case report. JPRAS. 2013, Aug. 2, 2013:S1748-6815. http:/www.jprasurg.com/article/S1748-6815(13)00440-3/abstract.

22. Lari AR, Kanjoor JR, Vulvoda M, Katchy KC, Khan ZU: Orbital reconstruction following sinonasal mucormycosis. Br J Plast Surg. 2002, 55:72-75.

23. Paloma V, Samper A, Cervera-Paz FJ: Surgical technique for reconstruction of the nasal septum: The pericranial flap. Head Neck. 2000, 22:90-94.

24. Hobar PC, Burt JD, Masson JA, Merritt JA, Trawnik R: Pericranial flap correction of superior sulcus depression in the anophthalmic orbit. J Craniofac Surg. 1999, 10:487-490.

25. Chang DW, Langstein HN, Gupta A, De Monte F, Do KA, Wang X, Robb G: Reconstructive management of cranial base defects after tumor ablation. Plastic and reconstructive surgery. 2001, 107:1346-1357.

26. Thaller SR, Donald P: The use of pericranial flaps in frontal sinus fractures . Ann Plast Surg. 1994, 32:284-287.

27. Argenta LC, Friedman RJ, Dingman RO, Duus EC: The versatility of pericranial flaps . Plast Reconstr Surg. 1985, 76:695-702.

28. Gadre AK, O'Leary M J, Zakhary R, Linthicum FH, House WF: The lateral skull base: A vascular perspective with clinical implications. Skull Base Surg. 1991, 1:110-116. 